sodium bicarbonate neutralized by Ioo parts of the sample, and where there is a considerable difference between the hot and cold tests, this should be stated, as it is an important factor in deciding as to the suitability of a tartar substitute for any particular use.

The best grades in the market have a neutralizing strength of ioo parts equivalent to forty-four to forty-five sodium bicarbonate, $i . e$, about the working strength of cream of tartar.

[CONTRIbltions from the ANaIytical laboratories of the SChool of Mines, Columbia Collfigf, No. 3.]

\title{
THE ANALYSIS OF VARNISHES.
}

BY PARKER Ci MCILHIYEY, PH.B., A.M Received March $3 i, 80.4$

$A^{\mathrm{T}}$ present varnishes are seldom analyzed because no means the amounts of the substances composing them. The tests used are practical ones and usually consist in varnishing a suitable surface with the sample to be tested and subjecting the varnished object to treatment as nearly as possible like that which it will receive in practice. If it is desired to ascertain the proportions of the different constituents, practical vamish-makers claim to be able to make up samples which will match in properties one to be tested, and in this way to arrive at the proper result. However this niay be, it is out of the question for the chemist who is not a varnish-maker to use such a process. If methods can be devised whereby a chemist can make an actual analysis with a fair degree of accuracy, buyers can be certain of what they purchase and manufacturers can work more intelligently.

The different kinds of varnish may be classified as follows:

I. Spirit varnishes.

2. Volatile oil varnishes.

3. Fixed oil varnishes.

4. Miscellaneous; collodion varnishes, etc.

Spirit varnishes are composed of a resin dissolved in alcohol. Shellac spirits," made by dissolving shellac in wood or grain alcohol, is the most common. 
Volatile oil varnishes are made by dissolving a resin in turpentine. Dammar varnish is a good example. Benzine is largely used as a substitute for turpentine in this and other varnishes.

The most important class is the fixed oil varnishes, and it is the analysis of this sort which will be considered. They are made from linseed-oil, a resin, and turpentine.

The principal resins used are kauri, manilla, and hard copals, such as Zanzibar. Common rosin is largely used as an adulterant. Kauri is the resin used by far the most, and there are many grades, varying in price from three cents to sixty cents a pound. Manilla stands next in the amount used, and of the others comparatively small quantities are used.

The resins used in fixed oil varnishes are in their natural state insoluble in linseed-oil and in turpentine. It is only after undergoing a process of roasting or distillation that they become soluble, and in this operation they loose from twenty to twenty-five per cent. in weight. In the process of manufacture the resin is first melted down in a kettle, and after it has been sufficiently heated the proper quantity of linseed-oil, also hot, is added, and the mixture heated some time longer to effect a combination between the oil and resin. After cooling somewhat, sufficient turpentine is added to properly thin the varnish.

It is difficult for several reasons to obtain samples of varnish for experiment in which the proportion of the constituents is known. They cannot be made successfully in small quantities as they are then of poor quality, and results obtained from such samples cannot be trusted. Through the kindness of Prof. A. H. Sabin, three samples of varnishes of known composition were obtained for experiment.

The Determination of Turpentine.-H. J. Phillips (Chem. Nezes, 63, 275, and J.Soc. Chem. Ind., 10, 577) proposes to distill off the turpentine at $220^{\circ} \mathrm{C}$., using about I 50 grnms of varnish and catching the distillate in a tared flask. A current of coalgas is passed through the liquid to prevent oxidation of the linseed-oil, and at the sanie time to assist in the removal of the turpentine vapor by carrying it away as fast as formed, and by agitating the liquid. The method is open to several objections; any vapors of naphtha in the coal-gas used are likely to be caught 
and contaminate the turpentine. This difficulty would be overcome by the use of carbon dioxide instead of coal-gas, but carbon dioxide is not usually available in sufficient quantity. The author does not use any condenser, but depends upon the cooling of the neck of the retort used by the air, which is not sufficient. The residue left after most of the turpentine is gone is very viscous and retains some turpentine very persistently.

Mills $(J$. Soc. Chem. Ind., 5, 222) says that the rolatile constituents of varnish are easily determinable by evaporation with water.

Attempts were made to effect the removal of turpentine by distilling it off in a vacuum. Trials were first made using twenty-five grams of substance and a temperature of $100^{\circ}-$ $120^{\circ} \mathrm{C}$, but this proved to be much too low a temperature and it was subsequently found that by using five grams instead of twenty-five grams of substance the results were better.

The method used was as follows: A portion of the varnish is weighed into a tared, round-bottom flask which is then heated in a paraffin bath at a temperature of $180^{\circ} \mathrm{C}$. for four to eight hours, the air and vapor being removed from the interior of the flask by a pump. The flask is then again weighed and the loss in weight represents turpentine.

The results by this method were as follows:

\begin{tabular}{|c|c|c|c|}
\hline Varnish used. & $\begin{array}{l}\text { Per cent. of turpen- } \\
\text { tine found. }\end{array}$ & Per cent. present. & $\begin{array}{c}\text { Quantity of substance } \\
\text { used. }\end{array}$ \\
\hline & $\cdots \cdots 52.7$ & 60.0 & 25 grams. \\
\hline & … 34.9 & 41.4 & 25 \\
\hline$C \cdots$ & $\cdots \cdots 5^{2.7}$ & 56.9 & "' \\
\hline
\end{tabular}

The results are thus seen to be too low and irregular, and the residues smelled of turpentine. It was found that these traces of turpentine could be removed, and correct results obtained by adding to the contents of the flask after cooling two or three cc. of petroleum ether of very low boiling-point, allowing the residue to dissolve, and then carefully exhausting the flask of air, and finally heating gently. Of course, in these experiments it is necessary to use round-bottom flasks. The great objections to this method are that it does not distinguish between turpentine and any other volatile substance, and also that it requires arrangements for exhausting air, which are not always available. The 
non-volatile residue is, however, in the very best condition for further examination.

Another method which has been used is a determination of the loss in weight on evaporating off the turpentine in the airbath at $100^{\circ} \mathrm{C}$. from a quantity of varnish contained in a watchglass. This method is open to the same objections as the previous process, and the residue is not in good condition for further examination on account of the drying of linseed-oil. The fact that linseed-oil increases in weight on exposure to the air tends to give too low results. The formation of a film of dried varnish preventing further evaporation renders it necessary to use only small quantities of substance. In experimenting with the process it was found better to use watch-glasses of flat form than the ordinary concave ones. Three-quarters to one hour exposure at $100^{\circ}$ and 0.400 to 0.500 gram substance gave the best results.

The following figures were obtained in this way: Varnish. Amount found.

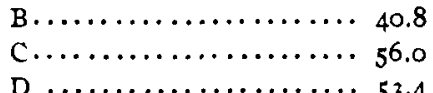

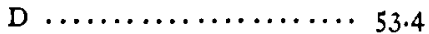

The requirements of a satisfactory process for determining turpentine are:

(I) That the volatile material shall be separated under conditions which admit of its being actually weighed or measured and then submitted to further treatment.

(2) That the non-volatile portion shall be subjected to as little heat as possible, both to avoid any. destructive distillation and to leave it unaltered for further examination.

(3) The process should require no unusual apparatus. None of these processes fulfill the above conditions.

It is well known that on distilling together two immiscible liquids, such as carbon disulphide and water, the boiling-point of the mixture is lower than that of the more volatile liquid. Carbon disulphide boils at $49^{\circ}$, but when distilled with water the boiling-point of the mixture is $43^{\circ}$ (Kundt, Jahresb. Fort. Chem., r87o, 49).

On distilling together $100 \mathrm{cc}$. of water and five cc. of turpentine it was found that the first ninety-five $c c$. of distillate contained all the turpentine which separated very well from the 
water. Experiment showed that ninety cc. of water either dissolve or hold in suspension permanently about 0.3000 gram of turpentine. On these principles the following process was devised:

Twenty-five grams of varnish are weighed into a flask of 400 cc. capacity, in which has been placed a piece of granulated tin, or its equivalent, to prevent bumping and about ten cc. of water. The flask is in this way prevented from becoming greasy, which would cause violent bumping. The contents of the flask are now submitted to distillation, the distillate being caught in a tapped separator. When ninety or ninety-five cc. of water have come over, the distillation is stopped and the turpentine and water allowed to separate. If the contents of the flask still retain any odor of turpentine more water should be added and the distillation resumed. After settling for a sufficient length of time, the water is carefully drawn off and the turpentine poured into a tared flask and weighed. A correction is made for the amount of turpentine retained by the water, anounting to 0.300 gram for ninety $c c$. of water. In some experiments salt was added to the water to raise its boiling-point, but no apparent advantage was gained except when the non-rolatile residue was heavier than water; in this case the salt prevented the residue from sinking to the bottom and causing bumping by greasing the flask. If it is desired to examine the residue, the remaining water is poured off from it and alcohol added. On distilling off the alcohol, and if necessary. removing the last of it by the addition of a little ether, which is also evaporated off, the residue is obtained pure.

The following results were obtained by this process:

\begin{tabular}{|c|c|c|}
\hline Varnish. & Per cent found. & Per cent. present \\
\hline$B \ldots$ & $\cdots 4 \pi .2$ & 41.4 \\
\hline$c \ldots$ & $\cdots \cdot 57.1$ & $5^{6.9}$ \\
\hline$D \ldots$ & ... 56.3 & 56.8 \\
\hline
\end{tabular}

The sample D was made by dissolving common rosin in turpentine, and it was therefore more difficult to remove the last trace of turpentine from the non-volatile residue than it ever is in an oil varnish, but even in this case the result is fairly accurate.

The method requires no unusual apparatus and can be carried out in about half an hour. The residue is not heated above the 
boiling-point of water, and the turpentine is actually weighed and may be itself analyzed.

For the determination of benzine in turpentine, the method of Burton ( $\mathrm{Am}$. Chem. $J ., 12$, IO2) gives the best results. It depends upon the conversion of turpentine into acids soluble in water by the action of nitric acid while benzine remains unaffected and is separated and measured or weighed.

The Non-volatile Portion. - The analysis of the residue consisting of linseed-oil and resin, both more or less altered by heat, presents an extremely difficult problem in proximate analysis and one which yet remains unsolved.

The properties of resins have been investigated analytically by; Hirschsohn, Pharm. Ztschr.f. Russland, 1875,225 , and $1877, \mathrm{I}$; Pharm. Jour., 7, 369, and 8, 389.

Schmidt and Erban, Sitz.d. Wiener. Akad., 94, 917, and Ztschr. angew. Chem., 1889, 35 .

Mills, J. Soc. Chem. Ind., 5, 222.

Mills and Muter, J. Soc. Chem. Ind., 4, 96.

Williams, Chem. News, 58, 224.

These investigators have made upon various resins the same tests which have been used in the analysis of oils; viz., the acid figure, the Koettstorfer figure, the iodine figure, the per cent. of bromine absorbed, and the solubility in ether, alcohol, etc. Their results are given in the following table:

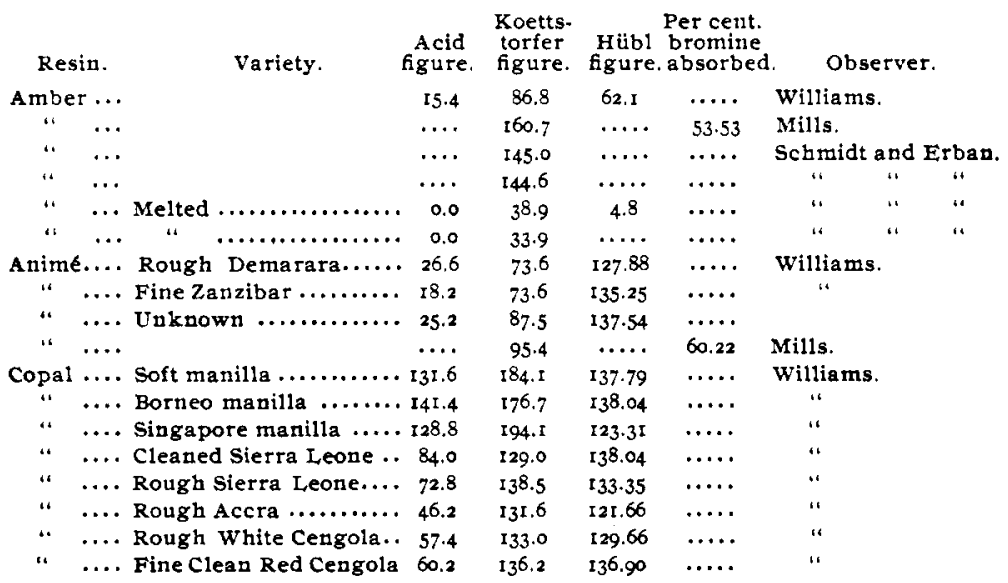




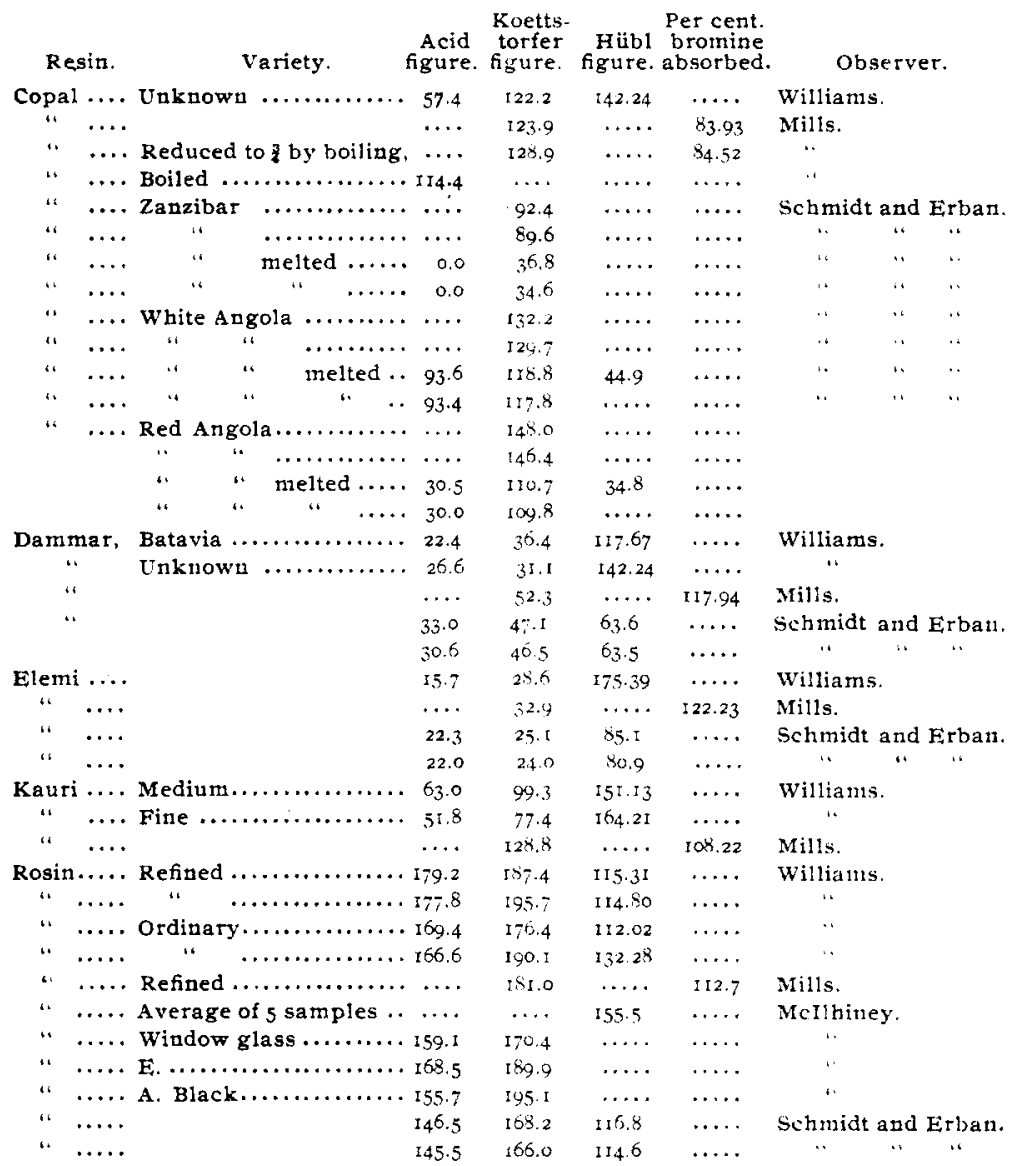

The corresponding figures for linseed-oil are as follows:

Acidity should be 0.0 . Mills allows one per cent. $\mathrm{KOH}$ for acidity.

Koettstorfer figure (Allen, Commercial Organic Analysis, 2, 42). Nine samples, I 87.4-195.2.

Hübl figure (Allen, loc. cit., 50). Raw oil, 155-160; boiled oil, 148. Holde, Mittheil. K. tech. Vers. Berlin, $1891,9,8 \mathrm{I}$, and J. Soc. Chem. Ind., 12, 179-180, 954.

Bromine absorption (Levallois, J. pharm. chim., 1887, 1, 334), roo per cent. 
Mills ( $J$. Soc. Chem. Ind., 2, 436). Raw oil, 76.09 per cent.; boiled oil, 102.36 per cent.

McArthur ( $J$. Soc. Chem. Ind., 7,64). Raw oil, 65.0-65.3 per cent. ; boiled oil, 63.2-66.3 per cent.

The differences in solubility between linseed-oil and melted resins are but slight and are of little value in effecting separations in varnish analysis.

The Hübl figure is evidently useless as a means of quantitative analysis for the figures of linseed-oil and kauri the most frequently occurring resin, are almost identical.

The difference between the Koettstorfer figure is only about seventy-five, and even supposing that the figures of both oil and resin are known accurately, which is not the case, it would be difficult to make the analysis so carefully that the percentages of oil and resin would be correct.

Mills states that the analysis may be made by determining the acidity to phenolphthalein, and this proved to be correct, provided the mixture is composed of common rosin and linseedoil and is not heated long. An analysis of such a mixture gave correct results but on attempting to apply the process to properly made varnishes the process was unsuccessful. Ten grams of a sample of varnish, known to contain 14.36 per cent. of kauriresin, were diluted with a mixture of absolute alcohol, ether, and petroleum ether to obtain a clear solution, and then titrated with a solution of caustic soda in alcohol using phenolphthalein as indicator. The acidity found in this way was equal to only $0.345^{\circ}$ per cent. of potassium hydroxide; this would mean an acidity of 2.40 per cent. for the kauri present, whereas Mills found I I.44 per cent., and Williams 6.3 per cent. Mills' statement that 'it is evident that boiled oil when heated with a resin makes no difference in the resin's acidity," is not sustained by the facts.

The amount of bromine absorbed, as determined by the methods of Allen, Mills, and Levallois, is of no more use than the Hübl figure. The results depend largely upon the conditions under which the analysis is conducted.

In view of the fact that the bromine-addition figure of rosin is 0.0 , while that of linseed-oil is 102, it seemed very likely that by means of this figure it would be possible to analyze varnish 
residues. To test the process, a mixture was made of fifty per cent. common rosin and fifty per cent. oleic acid. The bromineaddition figure of the oleic acid used was 51.78 per cent., and that of the mixture 25.7 per cent. corresponding to 49.6 per cent. of oleic acid instead of fifty per ant. In order, if possible, to obtain samples of boiled oil and kauri-resin in the same cot1dition in which they are present in varnishes, a quantity of boiled oil was heated in a retort to a temperature of $290^{\circ} \mathrm{C}$. and maintained at this temperature for one hour. A sample of clear kauriresin was also heated in a retort until it had lost twenty-three per cent. of its weight. The non-volatile part of a varnish of known composition was analyzed at the same time. The figures obtained were as follows:

\begin{tabular}{|c|c|c|}
\hline Substance. & $\begin{array}{l}\text { Bromine- } \\
\text { addition } \\
\text { figure. }\end{array}$ & $\begin{array}{l}\text { Bromine- } \\
\text { substitution } \\
\text { figure. }\end{array}$ \\
\hline ated linseed-oil & $7^{6.62}$ & 4.82 \\
\hline [elted kauri-resin $\ldots \ldots \ldots \ldots \ldots \ldots \ldots$ & . 21.53 & 80.31 \\
\hline $\begin{array}{l}\text { Jon-volatile of varnish }(\ldots \ldots \ldots \ldots \ldots, \\
\text { Cauri, } 54.3 \text { per cent., oil, } 45.7 \text { per cent. }\end{array}$ & 89.16 & 22.84 \\
\hline eoretical figures of abov & 46.71 & $45.8 \mathrm{I}$ \\
\hline
\end{tabular}

The process therefore fails to give any means of making this analysis on account of changes made by the process of manufacture in the properties of oil and resin. It is well known to varnish-makers that treating together, effects remarkable changes in their physical properties, and that a certain amount of heating is necessary to make them knit together and work properly in the finished varnish.

Gladding (Am. Chem. J., 3, 416), has devised a process for determining common rosin in mixtures with fatty oils, depending upon the solubility of silver resinate in ether and the insolubility of silver oleate in the same medium. This process was tried on varnish but also failed to give satisfactory results. A varnish known to contain 14.36 per cent. of Kauri resin gave 25.9 per cent.

It is evident that the processes used in oil analysis are not adapted to the analysis of varnishes. The oil and resin react upon each other in some way not understood, giving rise to new compounds, and we must know something about what these compounds are, before the analytical problem can be solved. 